\title{
HÁ UMA VOZ FEMININA NOS MARES E NOS CONTINENTES DE LÍNGUA FRANCESA?
}

Josilene Pinheiro-Mariz

Nicole Blondeau

RESUMO: A autoria masculina sempre foi marcante na literatura de língua francesa. Porém, nos últimos anos, com a afirmação da literatura "francófona," é possível se ver a marca feminina impressa nessa produção literária. Portanto, neste artigo, trazemos reflexões sobre quem é essa mulher escritora que utiliza a língua francesa para a criação literária nos espaços em que a língua francesa é materna, oficial ou de comunicação. Destacamos, assim, que existe uma voz dessa mulher em sociedades bem diferentes umas das outras.

PALAVRAS-CHAVE: Literatura francófona. Mulher escritora. Interculturalidade.

ABSTRACT: Male authors have always been dominant in French language literature. However, in recent years, with the presence and acceptance of "Francophone literature, it has been possible to feel the female presence printed and expressed in this female literary production. Therefore, in this paper, some reflections are presented regarding who this female writer is, who uses the French language for literary creation in places where French is the mother tongue, official language or language for communication. Thus, we highlight female voices in societies as different from each other.

KEYWORDS: Francophone literature. Woman writer. Interculturality.

\section{INTRODUÇÃO}

Atualmente, a literatura produzida em língua francesa originária de países ditos "francófonos" tem se constituído em um fator de grande importância para o fortalecimento da literatura escrita em francês nesses espaços. Outro elemento que é, por certo, fundamental nesse âmbito, é pensar a respeito do papel da mulher escritora em sociedades tão distintas como, por exemplo, o Canadá ou Bélgica ou, ainda, alguns países da África subsaariana ou da África Mediterrânea.

Diretamente ligada ao fator da diversidade nos espaços francófonos, está o próprio termo francofonia. Por vezes, ligado à subserviência, o uso dessa égide está longe de ser ponto pacífico entre os usuários da língua francesa como língua materna, de comunicação, 
oficial ou veicular. Isso se dá pelo fato de o termo estar associado à histórica colonização. Isto é, a língua francesa, em muitos casos, foi a língua da imposição do colonizador, sendo esse o caso de países da África e de espaços marítimos como a Nova Caledônia, no oceano Pacífico, ou as Antilhas, no Atlântico.

Considerando todas essas particularidades, nos propomos aqui a apresentar um panorama da produção feminina de textos literários escritos em língua francesa fora da França metropolitana, o Hexágono europeu. Propomos uma reflexão sobre o papel da mulher escritora, que utiliza a língua francesa nos cinco continentes (África, América, Ásia, Europa e Oceania) e três oceanos (Atlântico, Índico e Pacífico). Buscamos identificar qual a função dessa literatura de língua francesa na perspectiva de escritoras que adotaram essa língua como a especial para a produção ficcional literária. Isso pode, naturalmente, nos revelar a diversidade da língua, mas enfoca, em particular, as especificidades culturais dos povos que compartilham de língua francesa em todo o mundo. Isso denota que a língua francesa é, do mesmo modo que a língua portuguesa no Brasil, uma língua de unidade em um espaço de diversidades.

Nesse sentido, esse panorama da produção literária de escritoras francófonas destaca também uma abertura para a mulher em um espaço que, tradicionalmente, sempre foi ocupado por homens. Ressalte-se que, segundo a Academia Francesa, essa língua possui apenas o substantivo masculino écrivain ${ }^{1}$ não suportando, portanto a feminização do nome; embora, em outros países dessa mesma língua como no Canadá (Quebec), por exemplo, se utilize livremente a versão feminina: écrivaine ${ }^{2}$. Portanto, colocar em destaque o fato de que existem muitas mulheres que produzem literatura de qualidade reconhecida internacionalmente, em um espaço majoritariamente masculino, é uma espécie de desvendamento de uma produção literária de beleza especial e rica em diversidade, constituindo-se, por essa razão, em um caminho especial para se conhecer o "outro", por meio da literatura, além de favorecer intensamente o respeito à cultura dos povos de língua francesa, ponto de onde se vê, claramente, um espaço essencial para se trabalhar as pontes interculturais a partir da literatura.

No que concerne à literatura francófona, é necessário evidenciar que se trata de uma literatura de grande destaque no conjunto da produção de língua francesa. Escritores de diversos lugares têm produzido uma literatura marcante e com cores e paisagens peculiares a

\footnotetext{
${ }^{1}$ Escritor. Oficialmente, não possui forma no feminino.

${ }^{2}$ Escritora.
} 
cada região. Muito provavelmente, por isso, essa literatura seja tão especial para se estimular a leitura literária nas aulas de língua francesa no Brasil. Em trabalho anterior, (PINHEIROMARIZ, 2011), destacamos que a "Literatura Mundo" seria um caminho determinante para se promover a leitura fruição em aula de FLE (francês língua estrangeira) no nosso país, uma vez que, dependendo do lugar da "literatura Mundo", o texto tem características tão próximas de nós que, para o leitor/aprendiz iniciante na língua, torna-se um caminho mais natural para se construir e apreender sentidos do texto literário.

Por isso, levando em conta a nossa realidade de Brasil, temos nos voltado para uma abordagem do texto literário que propicie a fruição a partir de textos francófonos de países com características semelhantes às do nosso país, tanto no que tange ao fato históricogeográfico, como especialmente, no que diz respeito aos fatores sociais e de como vivem tais sociedades. Nessa perspectiva, buscamos incitar, junto aos leitores/aprendizes do FLE, uma reflexão que propicie as trocas interculturais em aula de língua, além de, evidentemente, percebermos que esse procedimento configura-se como um caminho particular para se chegar aos textos canônicos da literatura francesa, a exemplo dos textos de Molière ou Victor Hugo, para citar apenas dois dos clássicos da literatura e da língua francesa.

Portanto, este artigo nasce de uma alentada reflexão sobre o lugar da literatura em aula de língua estrangeira e, em especial, a francesa. Isto porque língua e literatura constituem-se em dois eixos fundamentais do domínio das Letras; assim, pensar em literatura, sem pensar na língua que a constitui seria um sério equívoco, do mesmo modo que o contrário, uma vez que ambas se complementam. E é por essa razão que sempre nos voltamos para a raiz de nossas reflexões que estão ancoradas na não dissociação entre língua e literatura (SANTORO, 2007; PINHEIRO-MARIZ, 2008; BLONDEAU; ALLOUACHE, 2008).

A partir dessas ponderações, nos propomos a ressaltar, no âmbito do ensino de língua e literaturas de língua francesa, quão marcante pode se apresentar a literatura francófona. Para isso, em um primeiro momento, discutimos um pouco a respeito do próprio termo francofonia, considerando as suas particularidades e as gradações que esse nome traz consigo. Em um segundo momento, focaremos na escrita feminina no mundo "en français"; dito de outra forma, apresentaremos quem e como é essa mulher que produz literatura nos mais variados espaços do mundo francófono, para, então, destacarmos o clamor da mulher que busca sua vez através da voz da literatura escrita em francês, mesmo em países onde essa língua não é a mais utilizada pelos falantes. Assim, buscamos destacar a presença da mulher 
na produção literária de língua francesa que, atualmente, apresenta um papel preponderante no que diz respeito ao espaço feminino, sendo por isso, decisivo em diversas sociedades.

\section{OBSERVAÇÕES SOBRE A LITERATURA FRANCÓFONA}

No que diz respeito à relação entre língua e literatura no campo das Letras, nós nos indagamos: por que, no Brasil, não se promove o ensino da língua francesa por meio da literatura francofófona? Perguntas como essa muitas vezes refletem o quanto está arraigado em nós um pensamento de que a literatura em língua francesa que não é produzida na França parece ser uma literatura de "segunda linha". Refletir sobre a francofonia leva-nos, primeiramente, a pensar em um mapa do mundo, uma vez que não se pode pensar em francofonia sem que se considere esse imenso espaço no qual a língua francesa é instrumento de comunicação. Provavelmente, por esse motivo, pensar no mundo de língua francesa é idealizar uma grande viagem pelos continentes da terra, e pelos oceanos. Esse também é o posicionamento do secretário geral da Francofonia, Abdou Diouf (2007), ao afirmar: "La Francophonie dans le Monde est une invitation au voyage, une invitation à parcourir les espaces [...] Espace culturel, espace médiatique, espace économique, espace politique ${ }^{3}$ " (DIOUF, op. cit. p.5; itálico do autor). É, por certo, nesse espaço cultural, que enfocamos a nossa perspectiva, considerando-se, certamente, a francofonia como um espaço de viagens e, portanto, de trocas.

No entanto, mesmo com todo esse estímulo ao conhecimento do diverso, o termo francofonia está relacionado a um fator que traz consigo certo desconforto, pois se trata de um momento em que alguns países eram vistos, sob o olhar do colonizador francês, como inferiores à França e aos demais povos europeus, pensamento partilhado por todo esse continente. É no período que começa no século XVIII - época de grandes mudanças no pensamento europeu-, conhecido como Século das Luzes, que a Europa se vê como centro do universo. Por certo, o fato de muitos filósofos terem saído daquele continente, deu ao europeu uma enorme sensação de povo civilizado, ao contrário dos outros povos, os não europeus, logo, não civilizados. A partir desse pensamento, para o povo francês, nasce a noção de Belles

\footnotetext{
${ }^{3}$ A francofonia no Mundo é um convite à viagem, um convite a percorrer os espaços [...] Espaço cultural, espaço midiático, espaço econômico, espaço político.
} 
Lettres, isto é: a Belle Langue, associada à Belle Littérature 4 causando ainda nos nossos dias um considerável desconforto quando se trata de se proporcionar uma leitura literária, como se a língua francesa, especialmente, fosse elemento constitutivo de uma literatura para iniciados na arte literária.

Além dessa questão relacionada à língua, o século XVIII foi marcado por conquistas francesas. Na expansão ultramarina, observa-se a presença francesa nas Américas, onde foi fundada: no Brasil, a cidade de São Luís (1612, situada ao norte do país, capital do Estado do Maranhão) cidade na qual os franceses permaneceram por apenas três anos, até serem expulsos pelos holandeses, que foram, mais tarde, expulsos pelos portugueses. Ainda na América do Sul, tem-se a Guiana, onde fundaram Caiena e, além disso, houve a presença francesa no Canadá; no Caribe, Guadalupe e Martinica. No continente africano, a partir de um Tratado de Escravidão (Traité des Noirs), os franceses se estabeleceram na ilha de Gorée, (ou Ilha da Goreia) no Senegal, na ilha de Madagascar e na Ilha da Reunião. Os franceses instalaram-se também no sul da Índia, uma vez que a companhia das Índias Orientais, criada sob o Ministro Colbert, havia mudado para a cidade de Pondicherry e para Chandernagore, perto do Rio Ganges (BRAHIMI, 2001, p. 10).

Provavelmente, essa intensa colonização tenha desencadeado o sentimento de que a literatura em língua francesa produzida fora da França não é uma "alta literatura", isto porque, de um modo geral, o que não está na França (Europa) não seria tão bom, não sendo, portanto, bem acolhido pelo público e pela crítica. Portanto, é nesse ponto que convergem as discussões. Ora, se a França se estabeleceu em diversos países pelo mundo, ela pôde impor a sua língua como a língua da civilização, a Belle Langue; mas, e os países que estão no continente europeu e que tem o francês como língua materna? Nessa questão, reside a problemática, pois a Bélgica, por exemplo, não se vê como país francófono pelo fato de não ter sido colonizado pelos franceses, como alguns países da África; note-se que a Bélgica também teve a sua empreitada colonizadora no Congo, país africano. E o Canadá, é francófono porque houve colonização francesa? Essas inquietações ressaltam ainda mais o quanto pode ser intensa essa discussão.

Trazendo para a nossa realidade, podemos pensar na língua portuguesa (LP) do Brasil. Teríamos tido a LP como a língua de imposição? A História do Brasil é tão semelhante à de

\footnotetext{
${ }^{4}$ Belas Letras, como em belas Artes e, na sequência: Língua, Bela Literatura.
} 
países francófonos que seria impossível não se estabelecer essa comparação; pois sabe-se que a empreitada europeia, no Brasil, teve a presença Francesa, mas teve também a marca holandesa e, sobretudo, a portuguesa, a mais marcante dentre os europeus que estiveram nestas terras. A partir desses fatos, pode-se afirmar que a História, bem como a produção literária do Brasil também se assemelha à das regiões francófonas.

É importante destacar que uma abordagem da literatura francófona para leitores aprendizes de FLE se configura, portanto, em um espaço de abertura de mundo, é o que nos assinala Moura (1999/2007), pois permite um diálogo entre culturas. Isso se dá, por certo, diante da dimensão do termo criado pelo geógrafo Onésime Reclus, (1837-1916) com o intento de reunir pessoas de espaços muito diferentes e que tem na língua francesa, a língua da união; o elemento que aproxima os diferentes e os distantes em torno de uma única língua. Assim, uma pergunta ressoa: o que é, então, a literatura francófona? Tal questionamento é necessário visto que falar de francofonia é, naturalmente, convergir para a literatura, pois ela marca um povo e suas culturas.

Especialistas têm discutido sobre a noção do termo francófono, na perspectiva do conceito de literatura francófona, ampliando-a para além da proposta do geógrafo que primeiro propôs o nome.

Si l'épithète francophone, dans son usage courant, renvoie au fait de «parler français », quelle valeur, quel sens revêt cet adjectif dans l'appellation littératures francophones ? A quel cadre spatio-temporel réfèrent ces littératures ? Comment faut-il considérer le qualificatif « francophone »?: at-il une dimension littéraire ou dissimule-t-il un substrat de paternalisme ? (ALLOUACHE, 2010, p. 9).

O paternalismo ao qual se refere Allouache (op. cit.) estaria ligado à presença colonizadora da França. Isso ainda reverbera nos nossos dias e, por essa razão, se vê a literatura em língua francesa produzida fora da França como o substrato desse paternalismo. O fato é que, mesmo atualmente, a literatura francófona ainda é lida por uma minoria ou que

\footnotetext{
${ }^{5}$ Se o epíteto francófono, em uso corrente, refere-se ao fato de "falar francês", qual valor, qual sentido reveste esse adjetivo no nome de literaturas francófonas? A qual quadro espaço-temporal se referem essas literaturas? Como se deve considerar o qualificativo francófonos? existe uma dimensão literária ou ela dissimula um substrato de paternalismo. (ALLOUACHE, 2010, p. 9)
} 
vê o seu valor, ou por leitores que gostam do exótico, característica muitas vezes observada nessa literatura.

Nesse sentido, trazemos neste texto, o que poderia ser visto como uma proposta com minorias das minorias. Primeiramente, por sugerir a literatura em aula de língua, procedimento não muito aceito tanto por linguistas, quanto por literatos. Em seguida, por se propor textos literários da literatura francófona, uma vez que esta não é alta literatura. E, por fim, pelo fato de se pensar dentro desse âmbito, a literatura produzida por mulheres, em especial, quando se sabe que esse espaço é especialmente reservado para os homens.

\section{A ESCRITA FEMININA NO MUNDO “EN FRANÇAIS”}

Além da língua, evidentemente, a história, ao longo do tempo, mostra que tanto filósofos como homens da literatura deram muito pouco espaço para a mulher escritora. Sabese que, desde a Idade Média, havia produção literária feminina, embora isso tenha sido deixado no esquecimento de uma memória coletiva que não permitia a mulher ocupando um lugar que tradicionalmente não era seu. Em muitos casos, as mulheres escreviam e publicavam com nomes masculinos ou simplesmente eram silenciadas. No entanto, é preciso se destacar que sempre houve, na literatura francesa, mulheres que ousaram produzir literatura desde Christine de Pizan (1363-1430) até os nossos dias, passando por Madame de Staël, George Sand e Simone de Beauvoir, essas mulheres corajosas ocuparam, brilhantemente, um espaço de destaque no meio dos homens detentores da palavra literária.

Felizmente, no início do século XXI, é possível perceber que, ao redor do mundo, há mulheres que ocupam o espaço de escritora, mesmo se o padrão de idioma francês formalmente ainda não aceita o gênero 'escritora'. Mas, a língua francesa, como língua viva é "un maelström culturel, produit d'un brassage de cultures d'origines multiple [...]"6 (BOISSERON ; EKOTTO, 2011, p. 11-12). E é em meio a essa mistura de povos e culturas diversas que encontramos, hoje, as mulheres que escrevem suas dores, suas preocupações, suas lágrimas e o acaso feliz ou infeliz de se viver em uma sociedade ainda dominada pelo homem. É certo que de um modo geral, seja na Europa, seja na África, também em países não

\footnotetext{
${ }^{6}$ [...] um produto de uma mistura de várias das culturas de origem, turbilhão cultural [...] (BOISSERON;
} EKOTTO, 2011, p. 11-12) 
francófonos, como o Brasil ou os Estados Unidos, ao longo da história, a única voz feminina possível de ouvir é a voz marcada pelo silêncio.

Quanto à escrita feminina no vasto mundo francófono, não se pode afirmar nem que exista uma escritura tipicamente feminina; isto é, uma escrita com características como a docilidade ligada à mulher; tampouco que nessa literatura exista um tema recorrente nas obras. Inicialmente, dir-se-ia que essas mulheres escrevem sobre os seus sofrimentos e suas experiências vividas no ambiente familiar. E, por essa razão, é necessário que se ressalte que o espaço francófono é circundado por realidades bem diferentes umas das outras. Nesses universos, destaque-se que, na África, por exemplo, as mulheres vivenciam experiências diferentes daquelas vividas no Quebec ou na Suíça. Essa diferenciação é possível de perceber, por exemplo, quando se lê a nostalgia em um poema da quebequense Anne Hébert:

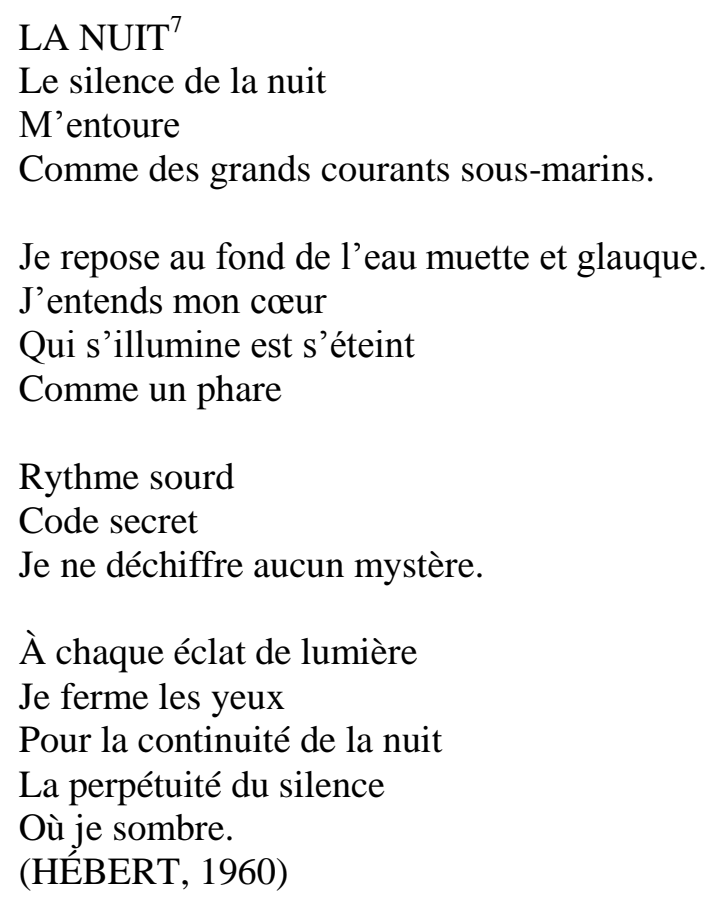

ou, então, na narrativa da argelina Assia Djebar, na qual se percebe certa mistura de beleza poética, resultado de um "pacto autobiográfico", que conflui para fatos que fazem ouvir, novamente, gritos que marcam a História de seu próprio país. Fatima-Zohra Imalayène, verdadeiro nome da autora, historiadora de formação, permite, a partir da leitura de seu

${ }^{7}$ Considerando a tradução literária como uma atividade específica e que demanda uma complexidade de fatores, opto por não fazer a tradução de nenhum dos textos literários transcritos neste artigo. No entanto, para que o leitor compreenda o encadeamento das ideias, eu redirei, em língua portuguesa, o que está na transcrição literária.

Neste poema de Anne Hébert, por exemplo, a poeta compara a noite, elemento que intitula o poema, a certo tipo de solidão que a cerca. No entanto, o eu lírico parece não rejeitar a situação, pois para ela diz "fechar os olhos a cada clarão da luz" para continuar no seu silêncio estimulado pela noite. 
romance L' Amour, la fantasia (1985), por exemplo, "Fazer ouvir, de novo, os gritos- de dor e de furor- de seus ancestrais: Aqui, não se trata de inventar, nem de descobrir [...], mas, de dar voz a documentos bem reais que até, então, dormiam nos arquivos" (HOLTER, 2003, p.2). ${ }^{8}$

Je reconstitue, à mon tour, cette nuit _ 'une scène de cannibales', dira un certain P. Christian, un médecin qui a vagabondé du camp français au camp algérien pendant la trêve de 1837 à 1839 . Mais je préfère me tourner vers deux témoins oculaires : un officier espagnol combattant dans l'armée française et qui fait partie de l' avant-garde.

[...] Le brasier, affirme-t-il, fut entretenu toute la nuit : les soldats poussaient les fagots dans les ouvertures de la caverne, 'comme dans un four'. Le soldat anonyme nous transmet sa vision avec une émotion encore plus violente : 'Quelle plume saurait rendre ce tableau ? Voir, au milieu de la nuit, à la faveur de la lune, un corps de troupes françaises occupé à entretenir un feu infernal ! Entendre les sourds gémissements des hommes, des femmes, des enfants et des animaux, le craquement des roches calcinées s'écroulant, et les continuelles détonations des armes !

Le silence des lieux est en effet troublé par quelques détonations d'armes ; Pélissier et son entourage y voient un signe des luttes intestines. Or ce brasier, admiré par l'armée comme une sculpture vivante et nécrophage, isole mille cinq cents personnes avec leur bétail. Ce témoin espagnol est-il seul, l'oreille contre la roche en feu, à entendre les convulsions de la mort en marche ${ }^{9}$ ? (DJEBAR, 1885, p 82).

E nos oceanos, os temas são sempre os mesmos? Em outras palavras, será que encontraríamos sempre textos que falam da beleza ou da alegria exótica (de acordo com uma visão europeia) de quem vive em uma área insular? Da Nova Caledônia, nos responde a contista, poetisa e mulher engajada politicamente, Gorodé Déwé que, com seu trabalho, busca fortalecer a literatura de identidade kanak (local) e francesa, mas com cores locais.
A quelques pas
du Jour de l'An
Un matin d'antan
par temps de vent
et temps de tempête
Quand tremblement

\section{La terre \\ Le corps}

\footnotetext{
${ }^{8}$ Faire réentendre les cris - de douleur et de fureur- de ses ancêtres: Il ne s'agit pas ici d'inventer, ni de découvrir [...] mais de faire parler des documents bien réels qui jusque-là dormaient dans les archives.

${ }^{9}$ Neste romance, Assia Djebar conta, nos silêncios, sobre os gritos de seus ancestrais. Em cenas de guerras e de amor, ela descreve as dores sofridas por uma voz feminina, chamada Argélia. Neste excerto, se lê uma cena de guerra, na qual o silencio parece falar mais forte que o próprio horror da guerra.
} 


\section{Le cœur \\ L'être}

Par tant de houle surgi en flash brouillé en histoire de fou Une folie d'amour De flou en mémoire En souvenir qui jaillit d'entre les feuilles mortes d'un carnet de route tombé au pied du mur de béton lunaire

Telles graines de pin colonnaire

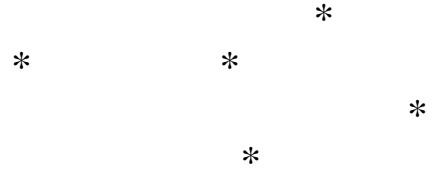

(DÉWÉ, 2009) ${ }^{10}$

A leitura de texto como esses nos levam a perceber quão importante é descobrir essa rica produção literária e pensar nesses textos como instrumentos que dão a voz às mulheres desse mundo de língua francesa. O fato de se ler esses textos de escritoras nos convida a pensar nas sociedades contemporâneas, isto é, nos conduz à discussão sobre as questões dos direitos humanos (e sobre as mulheres nessa conjuntura, obviamente) em cada uma das sociedades. Tal reflexão pode acontecer tanto a partir dos continentes, como dos oceanos, pois a proposta do intercultural permite um diálogo bem-sucedido sobre os valores culturais, despertando para as descobertas dos valores de cada um.

Para além da palavra "francofonia" e de tudo o que ela evoca em cada um de nós, nesse espaço, o Quebec, as Antilhas e a Guiana representam, claramente, a língua francesa na América. Certamente, esse mundo francófono reflete um exemplo cauteloso da sensação vivida em todas as Américas, que viria a ser o resultado da pós-colonização. Na América do

${ }^{10}$ Mais uma vez, um poema tão rico em metáforas e imagens, que traduzi-lo com um objetivo acadêmico, por certo não restituiria o seu valor poético. Entretanto, cabe a mim, tentar esclarecer a proposta da autora que, como poucos, busca uma valorização da identidade local (kanak).

Neste poema, o eu-lírico apresenta a necessidade de uma escrita local como um elemento inerente ao corpo, ao coração, ao ser; assim, percebe-se que, do mesmo modo, os grãos germinam, a língua pode estar presente no Ser. Esses grãos podem ser vistos no próprio poema não mais com palavras, mas por meio de símbolos caindo, germinando. 
Norte, esse sentimento é compartilhado tanto pelas antigas colônias britânicas, quanto pela antiga colônia francesa, o Quebec. Pensar em ex-colônias é também pensar na sensação "d'une domination politique, économique et symbolique propre aux populations minoritaires" $" 11$ (COMBE, 2010, p. 50).

\section{VOZES POR VEZ E POR VOZ}

Certamente, em cada um desses lugares no mundo, as vozes femininas, com suas peculiaridades, ressoam em busca de um espaço que lhe foi relegado ao longo de muitos anos. Assim, a partir deste último item, apresentaremos algumas das vozes femininas nos mares e nos continentes de língua francesa e, dessa forma, cremos dar voz a quem foi, historicamente, emudecida.

\subsection{VOZES CONTINENTAIS: ÁFRICA, ÁSIA, AMÉRICA E EUROPA}

Ao adentrar nas linhas da produção feminina em língua francesa, faz-se necessário ressaltar que embora os espaços francófonos sejam diferentes, a mulher escritora tem semelhanças em todos esses espaços, pois, seja na Europa ou na África, a mulher está continuamente em busca do seu lugar na sociedade. No que tange aos temas e gêneros literários, esses são distintos, dependendo da cada continente.

A escrita literária feminina na África apresenta temas de modo recorrente. Entre os preferidos, encontra-se a questão da infância, da língua/cultura dupla, da poligamia, da pobreza, do controle social; assim como o tema do feminismo, bem como uma poesia realista, só para citar alguns. No que diz respeito ao gênero das obras, encontra-se, sem dúvida, o romance autobiográfico, comum nas primeiras obras, momento no qual a narrativa como escrita literária busca ser mais consistente.

O romance autobiográfico é um dos principais gêneros praticados entre as escritoras do norte de África e do oeste desse continente, uma vez que é considerado como uma "pratique

\footnotetext{
11 “De uma dominação política, econômica e simbólica, próprias às populações minoritárias”. (COMBE, 2010, p.
} $50)$. 
d'avant-gard" 12 , visto que "l'écriture autobiographique est d'abord une pratique individuelle et sociale, qui n'est pas le seul fait des écrivains “ (LEJEUNE, 2007, p. 7) ${ }^{13}$. Nesse sentido, a escritora em toda a África escreve sobre os costumes e os hábitos daquele continente, do jeito que ele é; na verdade, ela o descreve, pintando-o com cores e tons da realidade que é, na maioria dos casos, uma realidade cruel. No que concerne ao físico ou sobre o corpo da mulher, é preciso sublinhar que as práticas “comme l'excision, l'infibulation, le mariage forcé, les brimades, humiliations et spoliations dont sont abreuvées les veuves ou les épouses stériles et répudiées [...]" (CHEVRIER, op. cit. p. 94) ${ }^{14}$.

Nos países da região africana conhecida como Maghreb e Machrek, ao norte do continente, região também conhecida, sob os olhos da colonização, como "África Branca", contraponto à “África Negra” ou África subsaariana, a mulher parece ter ainda menos espaço; todavia, essa negação de espaço instiga tanto as escritoras da região, que a produção nesses países é tão intensa quanto fundamentalmente "voz" por vez na sociedade. Assim, o papel social da mulher ou sua voz na sociedade, assim como a literatura, têm relação com o silêncio. Escrever textos de literatura, sobretudo nessa região é, historicamente, é uma profissão masculina, fator que é ilustrado pelos filósofos antigos, que serviram de modelo para a modernidade. A exemplo do contexto da Argélia, há esse silêncio histórico na literatura como certo esquecimento da história e da identidade feminina e é, naturalmente, por isso, que "L'écriture devient pour elles, tout naturellement, un moyen de survie existentielle" $\left(\right.$ NAHLOVSKY, 2010, p. 13) ${ }^{15}$. Essa seria uma das principais funções dessa produção feminina: uma espécie de espaço de resistência e resgate da memória.

Na região da África mediterrânea, existem muitas escritoras que ocupam esse lugar de voz, dentre elas, pode-se citar Assia Djebar, a mais importante na atualidade, Malika Mokedden, Laïla Sebbar, dentre muitas outras que denunciam os horrores vividos por mulheres em uma sociedade de predominância masculina. Do mesmo modo se vê na África subsaariana, mulheres que seriam os arautos, considerando-se que se (pré)ocupam em propagar a ideia de uma necessária mudança nos comportamentos da sociedade africana tão

\footnotetext{
${ }^{12}$ Uma prática de vanguarda

13 “a escrita autobiográfica é, primeiramente, uma prática individual e social que não é o único fato dos escritores" (LEJEUNE, 2007, p. 7).

14 “como a incisão, a infibulação, o casamento forçado, o assédio moral, humilhações e espoliações de que são saciadas as viúvas ou de esposas estéreis e repudiadas [...]” (CHEVRIER, op. cit. p. 94).

15 "A escrita torna-se, para elas, muito naturalmente, um meio de sobrevida existencial." (NAHLOVSKY, 2010, p. 13).
} 
diversa, mesmo das fronteiras continentais. Desde a década de 1970, escritoras como Mariâma Ba, Aminata Sow Fall e, nos dias atuais, Fatou Diome ou Calixthe Beyala são conhecidas por uma obra marcante que não apenas mostra a mulher como vítima da poligamia ou do descaso, mas também denuncia uma sociedade de homens e mulheres hipócritas.

Já a literatura de língua francesa na Ásia: Vietnam, Laos, Camboja (e Índia) é marcada por uma presença frequente de exploradores de diversas origens, com o objetivo de conquistar as riquezas naturais da região. Desse modo, a produção literária em língua francesa na Índia, por exemplo, foi intensamente alimentada pelo gosto do exótico, aspecto que o olhar europeu se ocupou em divulgar; nessa perspectiva, o que não era europeu, era considerado como exótico, em outras palavras, fora normal.

Quanto à literatura escrita por mulheres, nesses lugares, há quase uma ausência total de produção nesse continente, elemento que pode ser observado em antologias literárias da Ásia de língua francesa. No Camboja, cita-se, por exemplo, a escritora Makhali-Pahal (1899-1965), nascida em Pau (França) e filha de um administrador francês e uma mãe cambojana. Vivendo toda a sua infância no Camboja, ela seguiu um modelo literário de sua época, escrevendo uma literatura que reuniu características da literatura clássica, dos mitos, bem como de lendas do país.

$\mathrm{Na}$ atualidade, outras escritoras se ocupam em apresentar não somente as dores e sofrimentos das mulheres dessa região, mas de todo um povo que parece não ter voz no seu próprio ambiente. A exemplo dessa escrita, cite-se Linda Lê, que denuncia um exílio forçado, de um Eu em constante migração que

ne cesse pas de problématiser l'essence du moi, du moi migrant, du moi exilé, du moi originel, du moi dual de l'autre langue, du moi 'métèque' comme elle l'appelle, ce moi-métèque d'ailleurs dont elle écrit être orgueilleuse car le rencontre avec Cioran lui a permis de sortir de l'asphyxie de l'apatride pour réapprendre à vivre. (CRIPPA, 2006, p. 89) ${ }^{16}$.

Ao lado de Linda Lê, pode-se citar Ana Moï, que, no seu romance Riz noir narra o fim do colonialismo francês e o início do imperialismo norte-americano, a partir da história de

16 “não para de problematizar a essência do Eu migrante, do Eu exilado, do Eu original, do Eu dual de outra língua, do Eu 'estrangeiro', como ela chama esse Eu-estrangeiro, aliás, de quem ela escreve orgulhosa, pois o seu encontro com Cioran lhe permitiu sair da asfixia do 'ser sem pátria' para reaprender a viver". (CRIPPA, 2006, p. 89) 
duas irmãs torturadas em uma prisão sul do Vietname. Os acontecimentos ocorrem em 1968 e a história é baseada em fatos reais. Acrescente-se ainda os nomes de Ya Ding et Ying Chen, que têm uma literatura com marcas da tradição oral. Acima do exótico, a escrita da mulher na Ásia é semelhante à de Marguerite Duras, francesa nascida na Cochinchina, em 1914, sendo, portanto, uma escritora que parece denunciar uma sociedade em constante mudança e que vive no cruzamento entre culturas antigas e modernas.

Saindo da África e da Ásia, a literatura de autoria feminina, no Quebec, começa a ter espaço ainda nas primeiras décadas do século XX ; por volta dos anos de 1960, período de formação de uma literatura com características mais próximas da literatura quebequense dos dias atuais. Nesse espaço, a voz feminina não ficou enclausurada no esquecimento ou na submissão, como se percebe na literatura do continente africano.

Dentre as principais artesãs desse novo momento, cite-se Blais de Marie-Claire, cujo trabalho inclui peças teatrais, coleções de poesia e histórias e cerca de vinte romances. Em seus primeiros romances como La Belle Bête (1959), Tête blanche (1962) e Le jour est noir (1962), ela aborda temas ligados aos conflitos sociais, do peso do luto, da crueldade do desejo e de outras questões mais psicológicas. Mas, é uma Une saison dans la vie d'Emmanuel que a faz mais conhecida, porque é com esse romance que ela recebe o Prix Médicis em 1966, um ano após a sua publicação, no qual ela apresenta uma analogia à paisagem rural canadense, ressaltando as dificuldades promovidas pelo duro clima. Assim, Marie-Claire Blais se coloca como uma verdadeira escritora socióloga, apresentando os conflitos dessa escrita "mal de vivre", o personagem de Tête blanche, diz: "Écrire un roman, c'est savoir que chaque mot fait partie d'un immense trésor. Oh, si je pouvais un jour écrire des choses belles ! Ne pas écrire le désespoir, mais l'espérance ${ }^{17 "}$ (BIRON; DUMONT ; NARDOUT-LAFARGE, 2007, p. 440). Essa escritora ainda hoje continua a ter uma produção literária florescente, incluindo peças teatrais nas quais se discute a questão da mulher na sociedade e também narrativas autobiográficas.

No entanto, Marie Claire Blais não é única a produzir grandes obras literárias no Canadá de língua francesa, adicione-se ao seu nome, o de Germaine Guèvremont (18931968), Gabrielle Roy (1903-1983), Nicole Brossard (1943), Anne Hébert (1916-2000), Nancy

\footnotetext{
${ }^{17}$ Escrever um romance é saber que cada palavra faz parte de um enorme tesouro. Ah, se eu um dia pudesse escrever coisas belas! Não escrever o desespero, mas a esperança. (BIRON; DUMONT; NARDOUTLAFARGE, 2007, p. 440)
} 
Huston (1953), escritoras que são abundantemente lidas em todo o mundo e que, de modo geral, buscar mostrar o lugar da mulher na sociedade.

Quanto à francofonia na Europa (Bélgica, Suissa e Luxemburgo), lembrando-se da ressalva que esse termo sugere, toda a produção literária feminina é, igualmente, marcada por essa sutileza. Na Bélgica, por exemplo, a literatura produzida naquele país é "classificada" como literatura de língua francesa, sendo, dessa forma, colocada ao lado dos textos da literatura francesa e da luxemburguesa.

Le constat s'impose : la littérature francophone de Belgique s'inscrit dans un contexte politique hétérogène, dominé para la question nationale. Dès lors étaient posés le problème d'existence et celui de l'appellation de cette littérature. L'expression Littérature française de Belgique semble traduire le mieux la réalité. Elle souligne la spécificité d'une sensibilité inscrite dans le cadre d'une culturel plus vaste, persistant en dépit des brassages contemporains. (GORCEIX, 2000, p. 8) ${ }^{18}$.

Na Bélgica, pode-se citar Marie Gevers (1883-1975), que na sua obra apresenta um sentimento de nostalgia por sua região flamenga, ou ainda Suzanne Lilar (1901-1992), com uma obra que evoca lembranças da infância ou ainda Dominique Rolin (1913), com uma literatura que evoca conflitos humanos. No entanto, o nome de Marguerite Yourcenar (19031987) é, por certo, um dos mais marcantes da literatura desse país.

Assim, antes de encerrar as notas sobre a literatura da Europa de língua francesa, (excetuando-se a França) destacamos ainda duas escritoras: uma que atualmente é um dos grandes nomes da literatura do mundo em francês, a belga Amélie Nothomb e a outra que evoca nos seus contos "un monde déchiré par les contradictions, car "l’imagination luxuriante de Corinna Bille construit un monde à la fois violent et ingénu, composé des paysages entrevus, de souvenirs, de faits vécus, de fantômes, des visions" (BILLE, 1988, p. 8) ${ }^{19}$.

\subsection{VOZES OCEÂNICAS}

18 A observação é necessária: a literatura francófona da Bélgica se inscreve em um contexto político heterogêneo, dominado pela questão nacional. Desde então, colocou-se o problema da existência e da apelação dessa literatura. A expressão literatura francesa da Bélgica parece traduzir da melhor maneira a realidade. Ela sublinha a especificidade de uma sensibilidade gravada no contexto de uma cultura mais vasta, persistindo apesar das misturas contemporâneas. (GORCEIX, 2000, p. 8).

19، Um mundo dividido pelas contradições, pois a imaginação luxuriante de Corina Bille constrói um mundo às vezes violento e ingênuo, composto por paisagens entrevistas de lembranças, de fatos vividos, de fantasmas, de visões". (BILLE, 1988, p. 8). 
No que concerne às vozes oceânicas, destacamos os países localizados nas Antilhas, no oceano Índico e no Pacífico. Para Adamson (1997), nas Antilhas, a literatura escrita por mulheres tem o tom e o ritmo dos mitos antigos. "Elles parlent de moins en moins d'aliénation coloniale, et plus explicitement, elles dépeignent les préoccupations de leurs vies, telles qu'elles sont en train de la vivre"20 (ADAMSON, 1997, p. 9). A obra Elles écrivent des Antilles (RINNE; VITIELLO-YEWELL, 1997) reúne escritoras das ilhas que, mesmo dentro da diversidade, relatam realidades pessoais, ponto no qual as obras se aproximam.

Dentre os principais nomes da literatura produzida nas Antilhas: Guadalupe, Martinica e Guiana francesa (na América do Sul); Saint-Barthélemy, Saint Martin e Saint Pierre e Miquelon, ou ainda, no Haiti, há algumas que são essenciais para uma unidade da literatura francófona, dentre elas, destaque-se Maryse Condé, Yanick Lahens e Simone Schwarz-Bart, tendo, esta última, um papel especial no contexto da oralitura desses mares, uma vez que ela reúne em sua obra, a escrita da língua e o eco da tradição antilhana, tradição essa passada de geração em geração.

Foram as paisagens paradisíacas das ilhas desertas que atraíram e incentivaram a produção literária dos viajantes conquistadores dessas terras no oceano Índico. Esse tema do exotismo é recorrente na literatura de língua francesa, desde o século XII. Pode-se dizer que a intensa e diversa presença estrangeira tornou essa região um caldeirão de culturas e mestiçagens, tornando-a uma das mais ricas do mundo francófono. Por isso, é claramente um dos espaços mais profícuos para os diálogos interculturais, fazendo da língua francesa o elo de comunicação entre as ilhas (Madagascar, Ilha da Reunião e Ilhas Maurício), embora haja diferenças locais.

Il reste néanmoins une langue littéraire de référence, et son attraction dans ce domaine s'étend aux Seychelles et aux Comores où quelques tentatives de création se font jour. Selon la coexistence et la possibilité d'interférence avec d'autres langues, les stratégies d'utilisation du français en littérature ont été naturellement différentes d'une île à l'autre. (MATHIEU, 1998, 155$156)^{21}$.

\footnotetext{
20،“Elas falam cada vez menos da alienação colonial e mais explicitamente, elas as expõem as preocupações de suas vidas, tais como elas as vivem". (ADAMSON, 1997, p. 9).

21،"Resta, entretanto, uma língua literária de referência e sua atração nesse âmbito se estende até as ilhas Seychelles e às ilhas Comores onde há algumas tentativas de criação. De acordo com a coexistência e a possibilidade de interferência com outras línguas, as estratégias de utilização do francês na literatura foram, naturalmente, diferentes de uma ilha a outra". (MATHIEU, 1998, 155-156).
} 
Quanto à voz da mulher escritora, segundo Antoir et al. (2004), há três grandes nomes na literatura reunionesa; são elas: Marguerite-Hélène Mahé, Anne Cheynet, Graziella Leveneur e, como poetas, destacam-se Claire Karm e Lolita Mong. Está nos contos a principal força dessa literatura que utiliza a fórmula tradicional Kriké ! Kraké !, ${ }^{22}$ para a abertura das narrativas. Dentre as principais contistas, encontram-se: Claire Bosse, Joëlle Brethes, Isabelle Hoarau, Céline Huert.

Uma das principais escritoras reunionesas da atualidade é Amanda Devi, que nos confessa o quanto é particular trabalhar/escrever literatura tendo como principal instrumento a língua francesa. Devi traz uma reflexão sobre o jogo lúdico de (e com as) palavras que pode ser esse exercício de escrever em francês.

C'est un plaisir. Je sais que la langue que je pratique n'est peut-être pas toujours académique, j'essaie parfois de bousculer un peu les règles. C'est là qui est important, quand on écrit de la prose poétique, d'avoir une certaine liberté vis-à-vis de la grammaire. On peut juxtaposer les mots, comme on ne le ferait pas dans le langage traditionnel, parlé ou écrit. Dans les limites du possible, j'essaie de jouer avec la langue. C'est un plaisir maintenant [...] (DEVI, 2009, p. 37)

Para finalizar esta breve noção da produção reunionesa, é preciso se destacar que é a partir do gênero narrativo conto de tradição oral, transmitido de geração em geração, que a mulher tem seu espaço na litertura dessa região francófona. Nesses contos, ouve-se a voz feminina como aquela que embala a criança, fazendo-a dormir, dando, assim, à mulher, um lugar especial nessa literatura.

O continente da Oceania, nos termos da francofonia, é também parte do oceano Pacífico, formado por três coletividades: Nova Caledônia, Polinésia, e Wallis e Futuna. Na Nova Caledônia, existem vinte e oito línguas e cerca de cinquenta dialetos; a Polinésia reúne umas cinquenta pequenas ilhas e atóis, formando o POM (Pays d'Outre-Mer). Quanto à Wallis e Futuna, esse arquipélago forma o COM (Collectivité d'Outre-Mer).

\footnotetext{
${ }^{22}$ Expressão que corresponderia na nossa língua ao tradicional "Era uma vez".

${ }^{23}$ É um prazer. Eu sei que a língua que eu pratico, talvez nem sempre seja acadêmica; eu tento, às vezes, mexer um pouco as regras. É isso que é importante, quando se escreve uma prosa poética, é ter certa liberdade diante da gramática. Pode-se justapor as palavras, como não se faria em uma língua tradicional falada ou escrita. Nos limites do possível, eu tento brincar com a língua. É um prazer, agora [...] (DEVI, 2009, p. 37)
} 
A produção feminina, nessa região, tem nas ecritoras Déwé Gorodé, Anne Bihan, Catherine C. Laurent, Véronique Fillol e Imasango, suas principais representantes. De um modo geral, a obra dessas escritoras reflete uma inquietação quanto à condição de submissão da mulher na sociedade pós-colonial. Déwé Gorodé, por exemplo, tem um intenso trabalho de respeito pelas cores e paisagens locais, isto é, um cuidado em se trabalhar a diversidade, respeitando as particularidades.

Por certo, nesse aspecto, essa região da Terra é uma das mais propícias para favorecer as trocas interculturais, uma vez que o respeito ao outro se constitui em uma das principais

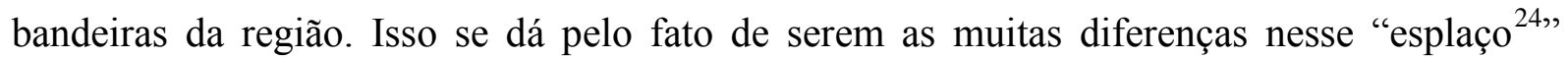
(MOKADDEM, 2008).

\section{CONSIDERAÇÕES FINAIS}

Tanto nesse espaço literário, conhecido como francófono, como em qualquer outro, as mulheres têm uma importância capital porque, na sua maioria, precisaram quebrar barreiras historicamente estabelecidas. Na África, por exemplo, é muito recente a mulher frequentar a escola e ainda é comum a dominação do homem sobre a mulher (DAYMOND et al., 2008). As próprias narrativas literárias de Assia Djebar ou de Mariama Bâ mostram o quanto a mulher busca seu espaço na sociedade, apesar das infibulações e do repúdio aos quais ainda são submetidas. São as próprias escritoras, sobretudo, dos países menos desenvolvidos, que narram fatos aterradores de submissão ao homem. Por isso, é certo que a escrita em língua francesa configura-se como o elo que as liga ao restante do mundo, favorecendo, assim, a oportunidade de serem ouvidas.

É necessário, entretanto, ressaltar o nosso ponto de partida: "Há uma voz feminina no mundo francófono?” A essa pergunta deve-se responder: Não há uma única voz que fala uma só língua, isto é, as escritoras francófonas não estão apenas em busca de seu "esplaço" nas suas respectivas sociedades. Isso é fato porque os vários espaços tais como continentes e

${ }^{24}$ O crítico Hamid Mokaddem (2008) criou o termo "esplace", que está relacionado ao lugar ("place", em francês) para dissociar, segundo ele mesmo (MOKADDEM, 2008, p. 17), do 'espaço literário', de Maurice Blanchot. Neste contexto, o termo, aqui aportuguesado como "esplaço", corresponde à mesma ideia de "lugar do literário', que é o mundo francófono. 
oceanos que têm no francês a língua de comunicação, administrativa ou materna são permeados de características distintas. Todavia, não se pode esquecer que mesmo com seus distintos aspectos, nos espaços de língua francesa, a escritora ainda parece ser porta-voz da mulher, por essa razão, deve-se dar voz a ela, em especial, no momento em que os seus textos são lidos.

É preciso ressaltar ainda que a revolução feminina é um pensamento novo e, então, a mulher ainda busca seu lugar na sociedade. E mesmo em países considerados mais desenvolvidos, a exemplo da França, observa-se que o lugar da mulher ainda está, por assim dizer, em fase de construção.

No âmbito da literatura, ler textos da francofonia é, por vezes, vencer barreiras que estão ligadas a uma rigorosa tradição literária; e, por esse motivo, colocamos a escrita feminina como uma dessas formas de se vencer barreiras, considerando-se que, ao longo da história, a escrita literária pertenceu particularmente ao homem escritor. Nesse sentido, nos propusemos a estabelecer um mapeamento da produção da mulher escritora de literatura pelos mares e continentes da Terra. Isso nos revelou que trabalhamos em uma perspectiva de minorias, pois, literatura francófona de 'pluma' feminina não estaria, por assim dizer, na ordem do discurso.

Considerando esses fatores, acrescentamos o fato de propormos tais textos literários para aulas de língua francesa, como um procedimento que estimula não somente a aprendizagem da língua francesa, mas, sobretudo, a leitura literária, não como uma pragmática, mas como a leitura de fruição, aquela que enleva e que convida à viagem, aspecto sob o qual a francofonia se torna um par ideal para a literatura nesse âmbito, uma vez que a francofonia é também um convite à viagem, confluindo, naturalmente, para promover os diálogos entre pessoas de culturas diferentes; isto é, as trocas interculturais.

\section{REFERÊNCIAS :}

ADAMSON, Ginette. Préface. In : RINNE, Susanne ; VITIELLO-YEWELL, Joëlle. Elles écrivent des Antilles. L'Harmattan : Paris, 1997. p. 9. 
ANTOIR, Agnès ; DAVID-FONTAINE, Marie-Claude ; MARIMONTOU, Félix ; POUZALGUES, Evelyne; SAMLONG, Jean-François. Anthologie de la littérature réunionnaise. Nathan: Paris, 2004.

BILLE, Corinna, S. Nouvelles et petites histoires. Choisies et préfacées par Jean-Paul Paccolat. Editions l'Age d'Homme : Monteux, 1988.

BIRON, Michel ; DUMONT, François; NARDOUT-LAFARGE, Élisabeth. Histoire de la Littérature Québécoise. Les Éditions du Boréal: Québec, 2007.

BLONDEAU, Nicole ; ALLOUACHE, Ferroudja. Littérature progressive de la francophonie. CLE International: Paris, 2008.

BOISSERON, Bénédicte; EKOTTO, Frieda. Voix du monde. Nouvelles Francophones. Presses Universitaires de Bordeaux: Pessac, 2011.

BRAHIMI, Denise. Langue et littératures francophones. Ellipses Éditions Marketing: Paris, 2001.

CHEVRIER, Jacques. Littératures francophones d'Afrique noire. ÉDISUD - Les écritures du Sud: Aix-en-Provence, 2006.

CRIPPA, Simona. De l'Indochine au Vietnam: agencement d'un espace littéraire en recherche et pour l'enseignement. In: CHAULET ACHOUR, Christine (Dir.) Convergences francophones. CRTF. Université de Cergy-Pontoise : Paris, 2006. p. 87-95.

COMBE, Dominique. Les littératures francophones. Questions, débats, polémiques. PUF Presses Universitaires de France: Paris, 2010.

DIOUF, Abdou. 2007. Préface. Valantin, Christian. (Dir.) La francophonie dans le monde 2006-2007. Nathan: Paris, 2007. p. 5.

DJEBAR, Assia. L'Amour, la fantasia. Livre de Poche : Paris, 1985.

DAYMOND, J. M. ; DRIVER, Doroty; MEINTJES, Sheila ; MOLEMA, Leloba ; MUSENGEZI, Chiedza, ORFORD, Margie ; RASEBOTSA, Nobantu (dir.). Des femmes écrivent l'Afrique. L'Afrique australe. Karthala : Paris, 2008.

GORCEIX, Paul. Littérature francophone de Belgique et de Suisse. Ellipses Éditions: Paris, 2000.

GORODÉ, Déwé. Graines de pin colonnaire. Madrépores : Nouméa. 2009.

Disponível em: http://lepetitmondedesmadrepores.blogspot.com.br/2009/08/extrait-tany-27decembre.html. Acesso em: 18, jan, 2012.

HÉBERT, Anne. Poèmes. Seuil: Paris, 1960. Disponível em: http://francais.agonia.net/index.php/poetry/160879/La_nuit. Acesso em: 18, jan, 2012. 
HOLTER, Karim. L'amour, la fantasia: écrire les cris Romansk Fórum. XV Skandinaviske romanistkongress. N. 16 - 2002/2. Universidade de Oslo.Oslo. 2002. consultado em 14 de março de 2012.

LEJEUNE, Philippe. Entretien avec Philippe Lejeune Une pratique d'avant-garde. Propos recueillis par Michel Delon. Les collections du magazine littéraire. Hors-série : Mes écritures du Moi. Le Magazine Littéraire. Mars-Avril, N 11 . SAS Magazine Expansion : Paris, 2007. p. 6-11).

MATHIEU, Martine. Deuxième partie. Océan Indien. In : HAUSSER, Michel ; MATHIEU, Martine. Littératures francophones : III. Afrique Noire et Océan Indien. Belin, SUP. Paris, 1998. p. 151-207.

MOKADDEM, Hamid. Littératures calédoniennes: La littérature océanienne francophone est-elle une littérture française ? : La courte échelle-éditions : Marseille, 2008

MOURA, Jean-Luc. Littératures francophones et théorie postcoloniale. PUF : Paris, 1999/ 2007.

NAHLOVSKY, Anne-Marie. La femme au livre: les écrivaines algériennes de langues française. L'Harmattan: Paris, 2010.

PINHEIRO-MARIZ, Josilene. Da necessidade de uma "Literatura-Mundo" no ensino do francês no Brasil. Revista Letras 42. UFRS. Porto Alegre, 2011.

Reflexões a respeito da abordagem do texto literário em aula de Francês Língua Estrangeira (FLE). Revista On Line Eutomia Revista de Literatura e Linguística. Recife: UFPE, p. 522-537, 2008, v. 2.

RINNE, Susanne; VITIELLO-YEWELL, Joëlle. Elles écrivent des Antilles. L'Harmattan: Paris, 1997.

SANTORO, Elisabetta. Da indissociabilidade entre o ensino de língua e de literatura: uma proposta para o ensino do italiano como língua estrangeira em cursos de Letras. Tese de doutorado. Faculdade de Filosofia e Ciências Humanas. Universidade de São Paulo. São Paulo. 2007. 299 p. + anexos.

RECEBIDO EM: 07 de maio de 2012

APROVADO EM: 11 de junho de 2012 